\title{
Rediscovery of Scarabaeus sevoistra Alluaud, 1902 (Coleoptera: Scarabaeinae): biological notes and IUCN Red Listing
}

\author{
Authors \\ ${ }^{1}$ Christian Michel Deschodt (i) \\ 2James du Guesclin Harrison (1) \\ ${ }^{1}$ Catherine Lynne Sole (1)

\section{Affiliations \\ 'Department of Zoology and Entomology, University of Pretoria, Private Bag X20, 0028 Hatfield, South Africa. \\ ${ }^{2}$ School of Animal, Plant and Environmental Sciences, University of the Witwatersrand Private Bag 3, WITS 2050, South Africa.}

\section{Corresponding Author}

Mr Christian M. Deschodt, e-mail: cdeschodt@zoology.up.ac.za

\section{Dates}

Submitted: 23 November 2020 Accepted: 4 August 2021

Published: 5 November 2021

\section{How to cite this article:}

Deschodt, C.M., Harrison, J. du G \& Sole, C.L., 2021, 'Rediscovery of Scarabaeus sevoistra Alluaud, 1902 (Coleoptera: Scarabaeinae): biological notes and IUCN Red Listing', Bothalia 51(2), a14. http://dx.doi. org/10.38201/btha.abc.v51. i2.14

Copyright: @ 2021. The Authors Licensee: SANBI. This work is licensed under the Creative Commons Attribution 4.0 International License.
Scarabaeus sevoistra Alluaud, 1902 was previously thought to be extinct. While identifying Scarabaeinae species on the iNaturalist website, photos posted by citizen scientists were discovered and identified as this species by the authors. The importance of the rediscovery of the species is presented here. We provide new biological notes for the species and a key to separate the species from its congeners. Additionally, we formally give a conservation status for the species.

Keywords: Scarabaeus sevoistra, iNaturalist, rediscovery, biological notes, conservation status.

\section{Introduction and taxonomic history}

The tribe Scarabaeini is one of four dung beetle tribes that occur on Madagascar (Philips, Pretorius \& Scholtz 2004; Monaghan et al. 2007), where it is represented by only three species of Scarabaeus Linnaeus, 1758. These species are morphologically distinct from one another and from other Scarabaeus and, consequently, as discussed below, have had an unstable taxonomic history (Sole et al. 2011). Of these three species, Scarabaeus sevoistra Alluaud, 1902 is rare and was only collected from two localities in southern Madagascar: Analavondrove in Antanimora (1901) and Marovato (1939). Tree felling and harvesting and the invasion by Opuntia Mill. has greatly reduced the natural habitat in those areas (https://www.worldwildlife.org/ecoregions/at1311). The species has not been collected or recorded during the last 82 years and was thought to be extinct or functionally extinct (Rahagalala et al. 2009).

The holotype of $S$. sevoistra, the only specimen of the type series, was collected by Dr J. Decorse, a French botanist and entomologist, who was collecting xerophytes (Aloe, Euphorbia and Sarcostemma) in Madagascar between 1898 and 1900 (Eggli \& Newton 2010). Alluaud (1902: 250) described it as Scarabaeus sevoistra Alluaud, 1902 and noted that the specimen was collected on the 'Androy plateau, in the north of the country of Sevoïstra, on a bush trail in the Analavondrove region, in February 1901' (our translation from French). Thereafter, Gillet (1911) erected the new genus Neateuchus for S. sevoistra together with the African continental species Scarabaeus rixosus Péringuey, 1901 and Scarabaeus proboscideus (Guérin-Meneville, 1844) (type species of the genus by original designation).

The defining features of Neateuchus as provided by Gillet are brief and include: 'the very close intermediate coxae, leaving an almost linear gap between them, and by the mentum offering a strong tooth perpendicular to its surface. The arrangement of the intermediate coxae places this genus closer to 
Mnematium MacLeay and Mnematidium Ritsema' (translation from (Gillet 1911)). Janssens (1938), on the other hand, believed that $S$. sevoistra differed enough from the two continental species to be placed in its own monotypic genus and erected Neomnematium Janssens, 1938 to accommodate it as Neomnematium sevoistra (Alluaud, 1902).

In hindsight, and presumably unknown to Janssens (1938), the characters used for the erection of Neomnematium relate to the species' modified morphology due to it being flightless, unlike the flying S. rixosus and S. proboscideus, and to its psammophilous adaptations (e.g., broad, spade-like clypeus) for digging into sand (Scholtz 1981, 2000). Paulian and Lebis (1960) and Ferreira (1961) followed this same generic placement. Mostert and Holm (1982) synonymised Neomnematium with Scarabaeus based on it having a similar protuberance on the mentum as Scarabaeus zambesianus Péringuey, 1901 and a similarly symmetrical aedeagus as is seen in Scarabaeolus scholtzi (Mostert \& Holm, 1982) and Scarabaeolus rubripennis (Boheman, 1860). Harrison and Philips (2003), Harrison, Scholtz and Chown (2003) and Forgie, Philips and Scholtz (2005) agreed with this decision following the first morphological phylogenies for the Scarabaeini. Forgie, Philips and Scholtz (2005) stressed that, despite the difficulty to obtain specimens of $S$. sevoistra and all the allied flightless Scarabaeini, it would be important to find more of them for further molecular and morphological studies and to gain a better knowledge about their biology.

Here, we update and discuss the known geographic records for Scarabaeus sevoistra, summarise its taxonomic history, expand on its natural history, and provide an IUCN Red listing to highlight its need for conservation and to facilitate the latter. In addition, we provide an identification key to differentiate the three known species of Madagascan Scarabaeini from one another.

\section{Materials and Methods}

iNaturalist (iNat) (https://www.inaturalist.org/home) is a website open to all where natural history images can be uploaded and stored with accompanying biological information. Specialists then voluntarily identify (where possible) the taxa in the photographs. Both the data and photos are accessible to scientists. Recently, C.M.D was making routine Scarabaeinae identifications on the iNat website and came across a peculiar-looking flightless scarabaeine beetle from Madagascar (Figure 1A-F). After consultation with J.duG.H. and C.L.S. and comparing the iNat photos with images of the holotype of Scarabaeus sevoistra Alluaud, 1902 housed in the Muséum national d'Histoire naturelle (MNHN), the identities of the listed iNat records are confirmed here to be $S$. sevoistra (Figure 2A-C).
Taxonomy from photographs is a contentious issue (Epstein 2017). Although we use photographs as a basis for this current paper, we believe that the necessary characters to identify the species are visible. The images are from three independent sources and thus most probably authentic. As this is a species of conservation concern, we do not need to collect specimens for the purpose of this paper.

\section{Results and discussion}

These new records of $S$. sevoistra constitute the first and only confirmed observations of this species in about 80 years. This rediscovery is of extreme importance as the species can now formally be protected and some of its biology inferred.

\section{Sexual dimorphism}

As can be seen in Figures 2A and C, the holotype of Scarabaeus sevoistra has some obvious differences from the specimen illustrated and identified with this same name by Paulian and Lebis (1960). The differences concern several features in the shape of the protibiae that, in other better-known species of Scarabaeini and dung beetles in general, are related to sexual dimorphism. More specifically, the holotype has the protibiae ending bluntly, as the proximal inside and outside denticles of the protibia ends in a T-shape; moreover, the inner edge of the protibiae is strongly serrated (Figure 2A). These features are typical of male dung beetles. Paulian and Lebis's specimen (Figure 2C), in turn, lack the denticle in the inner edge of the protibiae and, therefore, they do not end in a T-shape; furthermore, the serration on the inner protibial edge, is also lacking. These characters are typically female. Unlike the holotype, Paulian and Lebis's specimen also has the protibial outer teeth quite large, a condition that is also usually related to females and presumably function in the making of dung balls and for digging into sand. The original description does not mention the sex of the holotype but based on the features discussed above, we confidently conclude it is a male, whereas Paulian and Lebis's specimen is a female. Like other Scarabaeus, therefore, the protibiae of $S$. sevoistra are highly sexually dimorphic.

\section{Natural history and new biological notes of Scarabaeus sevoistra}

Harrison and Philips (2003) and Harrison, Scholtz and Chown (2003) made a detailed morphological analysis of the mouthparts of all known flightless species of Scarabaeini. They predicted that Scarabaeus sevoistra would be a wet dung feeder as it does not exhibit the mouthpart morphology ubiquitous to all species 

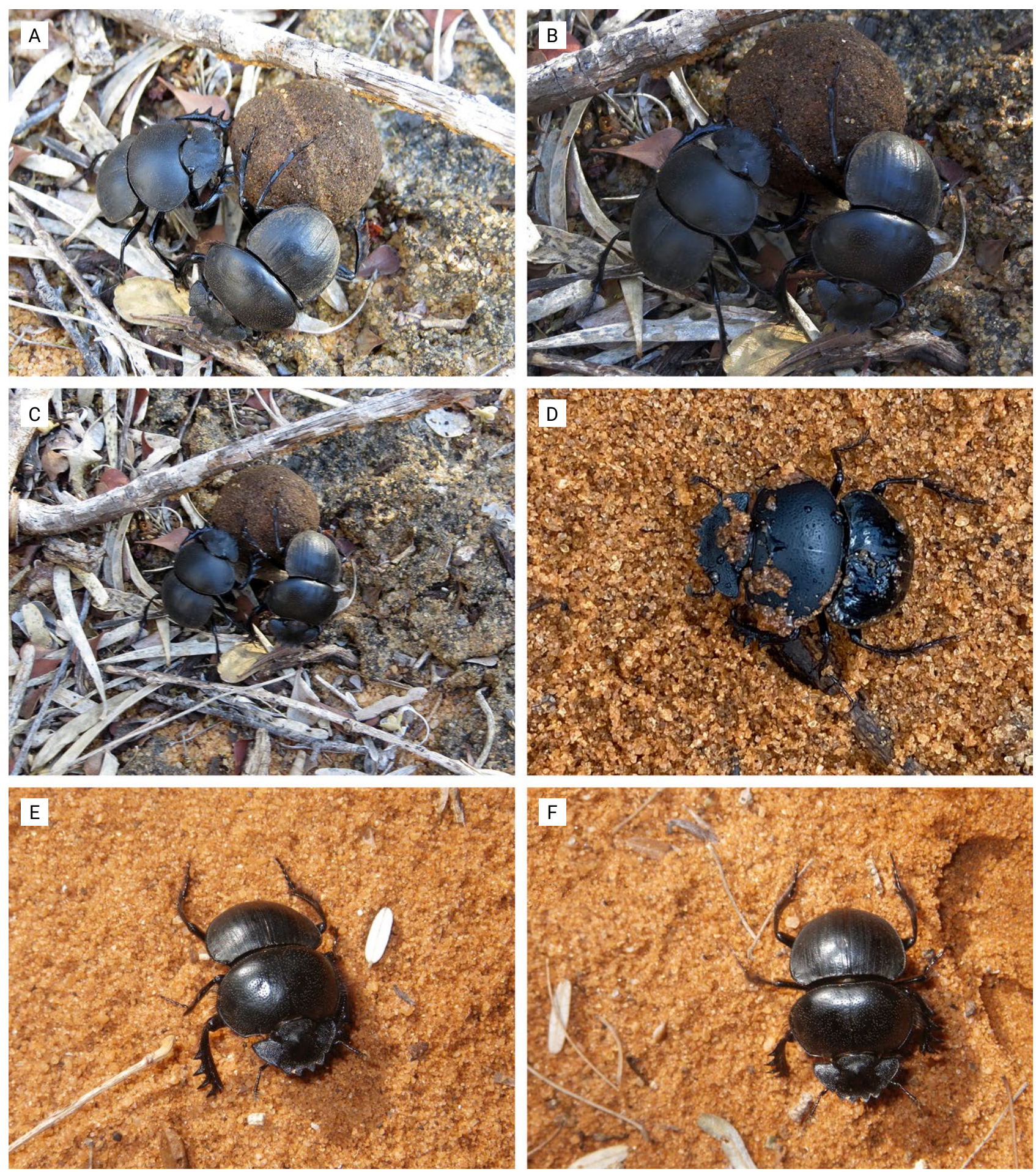

Figure 1. A-F, Recent photographic observations of Scarabaeus sevoistra Alluaud, 1902. A, B, C, photographed by Joseph Thompson, 04 November 2015; D, photographed by Bitty Roy, 17 November 2019; E, F, photographed by Maxim Nuraliev, 01 August 2015.

of Pachysoma Macleay, 1821, where dry dung and detritus feeding is the norm (Scholtz, 1989; Harrison, Scholtz and Chown (2003).

From the series of pictures of the three records found on iNat (Figure 1A-F), the following new biological notes for $S$. sevoistra can be inferred.

It can be confirmed that the species does indeed feed on wet dung as predicted by Harrison, Scholtz and
Chown (2003), based on the data about mouthpart morphology compiled by Harrison and Philips (2003).

It is known that when most ball-rolling Scarabaeini species pair up at the dung source, the male will roll it with the female clinging to the side of the ball as in Kheper and Scarabaeus or she will follow from behind as in Scarabaeolus (Davis, Frolov and Scholtz, 2008). It is apparent from the photos (Figure $1 \mathrm{~A}-\mathrm{C}$ ) that this species makes spherical dung balls that they roll backwards 


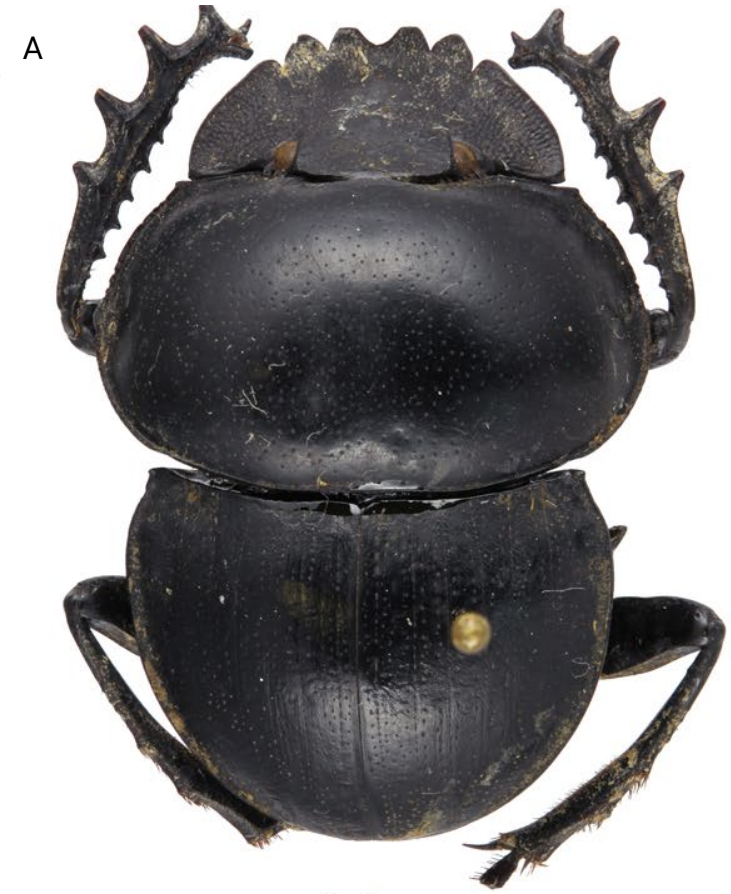

B

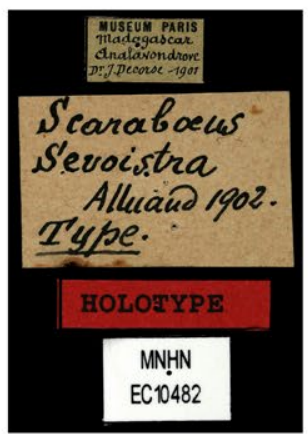

。

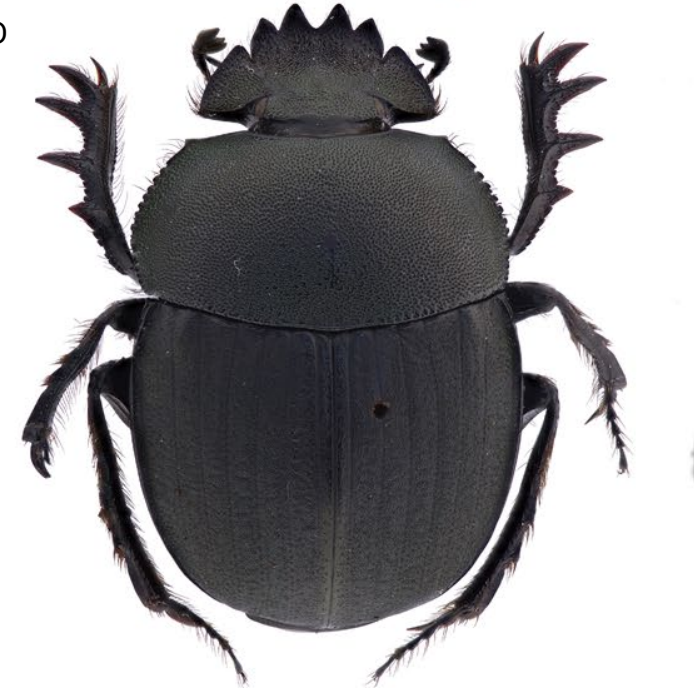

$\mathrm{E}$
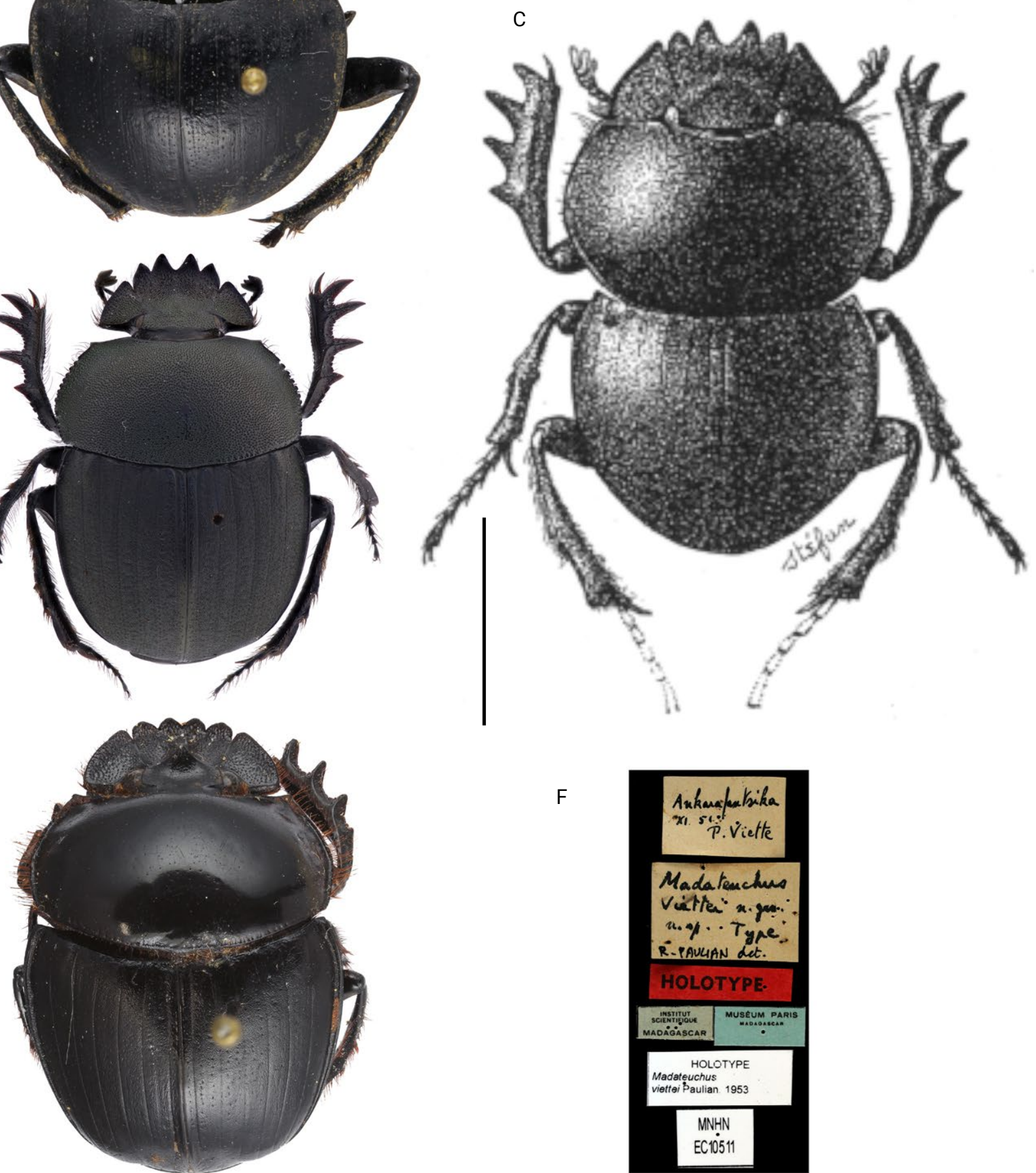

Figure 2. A-G, Madagascan Scarabaeini species. A, B, holotype male of Scarabaeus sevoistra Alluaud, 1902 and the associated labels from the MNHN; C, habitus drawing of a female S. sevoistra (from Paulian \& Lebis (1960: 14)) for comparison; note the dimorphism in the shape and form of the protibiae of the male (A) and female (C); D, Scarabaeus radama Fairmaire, 1895; E, F, Scarabaeus viettei (Paulian, 1953), holotype female and the associated labels from the MNHN. Scale bar is $10 \mathrm{~mm}$. 
while working as pairs, but it is unclear if the female intends to sit on top or cling to the side of the ball. We are aware that some species of ball rolling dung beetle can steal dung balls made by other telecoprid species, but the photographic evidence suggests that $S$. sevoistra does, at least, roll its own dung balls.

In all the available iNat photos, they are photographed on sandy soil, as occurring in all other known flightless Scarabaeini (all reviewed in Harrison, Scholtz and Chown (2003)). This is in accordance with the previous collecting record by J. Decorse, who, as explained above, also originally collected the species while searching for xerophilic genera of plants (Eggli \& Newton 2010). This constitutes further independent evidence for the association between arid areas with sandy soil and the evolution of flightlessness among the Scarabaeini (Scholtz 2000).

All the iNat specimens were observed in the Madagascan spiny thicket ecoregion, suggesting this to be their preferred habitat type (Figure 3). Both Verreaux's sifaka (Propithecus verreauxi Grandidier, 1867) and the ringtailed lemur (Lemur catta Linnaeus, 1758) are relatively large primates (weighing about 2-4 kg) that occur in the Madagascan spiny thicket ecoregion (LaFleur \& Gould 2020; Louis et al. 2020). Although S. sevoistra may be able to switch back to utilising cattle dung, as tentatively suggested by Rahagalala et al. (2009), for the
Malagasy Scarabaeini as a whole, it is possibly on the dung of these indigenous primates that the species naturally feeds and survives on.

Of the photographed specimens (Figure 1E-F), only one of the photographers (Maxim Nuraliev) noted soil and climate data. That specimen was observed on sandy soils on a cool, cloudy and wet morning, after a night of rain (Maxim Nuraliev, pers. com.). Paulian and Lebis (1960) include this biological note for the species: 'The species seems to be very localised and to have only a very brief period of appearance, probably linked to the rains' (our translation from the original French).

\section{Key to the Madagascan species of Scarabaeini}

The three species of Scarabaeini that occur on Madagascar are believed to have arrived there naturally (i.e. by non-human means) (Rahagalala et al. 2009; Sole et al. 2011)) and are thereby considered indigenous and endemic. Though this has not been recorded so far, all three species of Scarabaeini may potentially occur sympatrically. We thus provide a key to separate them from one another.

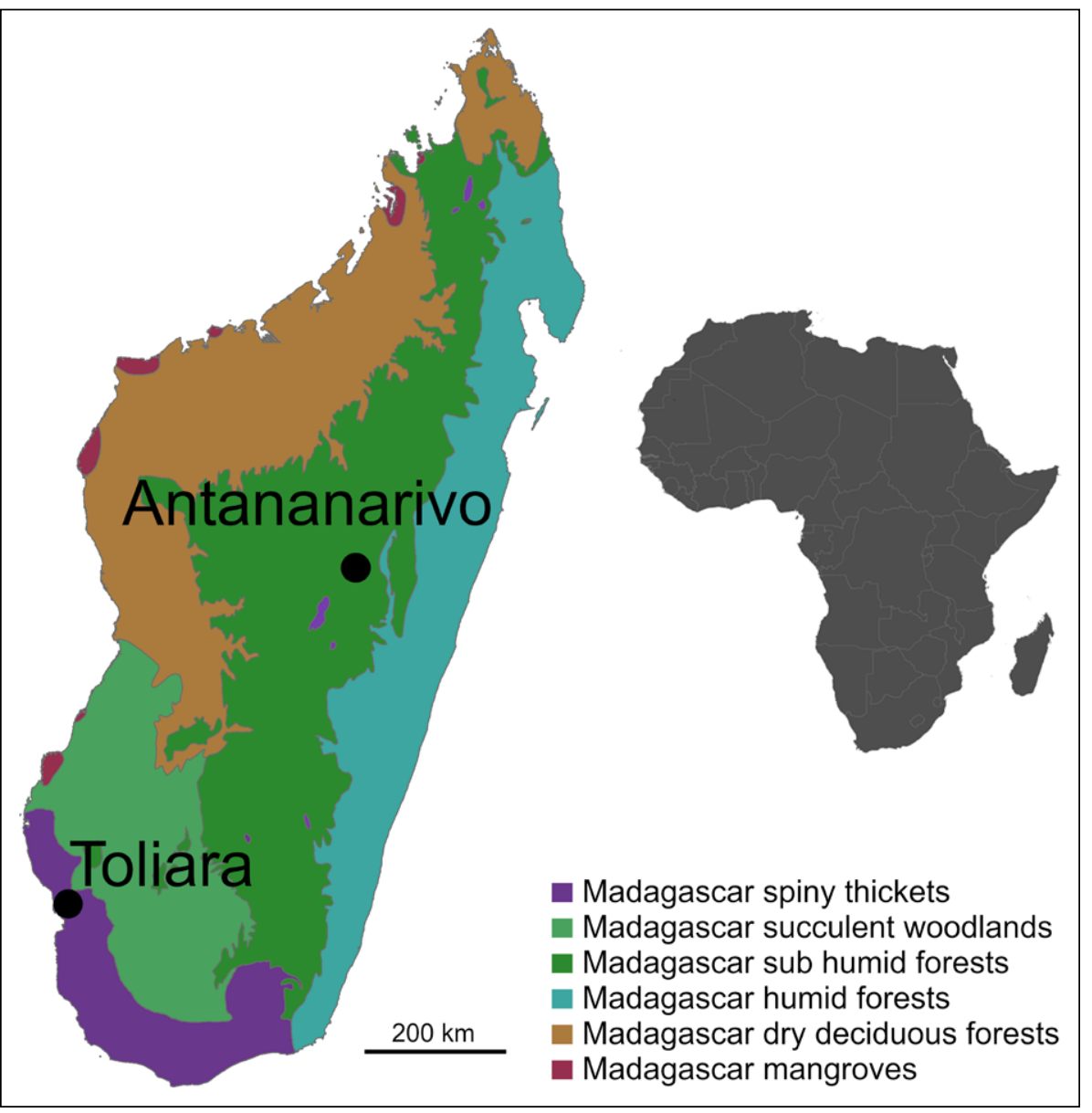

Figure 3. Map showing the ecoregions of Madagascar with the Madagascan spiny thickets in the southwest. 
Flightless. Elytra strongly rounded anteriorly. Southwest of Madagascar . . . . . . . . . . . . . . . . . . . . . . . . . . . Scarabaeus sevoistra Alluaud, 1902 (Figures 1A-F and 2A, C)

2a (1b) Pronotum and elytra smooth, with small punctures. South and southwestern Madagascar. . . . . . .

\section{Conservation status}

Recently quite a few specimens of Scarabaeus cancer (Arrow, 1919), a related and similarly enigmatic species from Angola, ended up for sale within the insect trade. To keep the rediscovery of $S$. sevoistra from hobbyist-collectors, Joseph Thompson, the citizen scientist who posted the first pictures, was asked to remove them by one of the authors here. However, two subsequent postings of $S$. sevoistra were made by different citizen scientists and we realised that a different approach was needed as news of its rediscovery would eventually reach these collectors. We thus decided to formally give this enigmatic species a Red Data List status as a measure of protection. Additionally, the authorities in the area where the species was photographed can now be informed of the scarcity and vulnerability of this species to poaching and be on the lookout for any suspect collecting activities.

Available distribution evidence suggests that $S$. sevoistra is geographically restricted to the already Critical/ Endangered (https://www.worldwildlife.org/ecoregions/ at1311) Madagascar spiny thicket ecoregion in the south of the country (Figure 3). The ecoregion is known to support an exceptionally high level of endemism while encompassing some smaller centres of endemism within the ecoregion (https://www.worldwildlife.org/ ecoregions/at1311). We specifically have not indicated on the map where the specimens were photographed, but the area that $S$. sevoistra was photographed in is a small area in the south of Madagascar with less than 100 ha that is afforded protection.

With only about $3 \%$ of this ecoregion formally protected, the most important threats to its survival are habitat destruction for livestock pasture, agriculture and conceivably poaching (https://www.worldwildlife.org/ecoregions/at1311) (Lindenmayer \& Scheele 2017). Although widespread, the Verreaux's sifaka is considered Critically
Endangered (Louis et al. 2020) and the ring-tailed lemur is considered Endangered (LaFleur \& Gould 2020) and thus the food source of $S$. sevoistra is probably also very limited. This dung beetle species should thus be assessed as Endangered B2ab (see IUCN (2012) for an explanation of the criteria), but future assessments might elevate the threat category to Critically Endangered.

\section{Acknowledgements}

We would like to thank Mario Cupello (Federal University of Paraná), and two anonymous reviewers for their invaluable comments that improved the earlier version of this manuscript and Joseph Thompson, Maxim Nuraliev (Lomonosov Moscow State University) and Bitty Roy (University of Oregon) for their keen observations and their permission to use their photographs. Christophe Rivier (MNHN) is thanked for imaging the holotype specimens of Scarabaeus sevoistra Alluaud, 1902 and Scarabaeus viettei (Paulian, 1953). We also thank the iNat website for allowing us to use the data. C.M.D. thanks the University of Pretoria for continued $\mathrm{PhD}$ bursary funding.

\section{Competing interests}

The authors declare that they have no financial or personal relationship(s) that may have inappropriately influenced them in writing this article.

\section{Authors' contributions}

C.M.D. (University of Pretoria) was the project coordinator, J.duG.H. (University of the Witwatersrand) conceived the paper and C.M.D. (University of Pretoria), J.duG.H. (University of the Witwatersrand) and C.L.S. (University of Pretoria) wrote the paper together.

\section{References}

Alluaud, C., 1902, 'Description d'un Coléoptère nouveau du genre Scarabaeus (Ateuchus) du Sud de Madagascar', Bulletin du Muséum d'Histoire Naturelle, vol. 8, no. 4, pp. 250-251.
Davis, A.L.V., Frolov, A.V. \& Scholtz, C.H., 2008, The African dung beetle genera, Protea Book House, Pretoria: pp. $1-272$. 
Eggli, U. \& Newton, L.E., 2010, Etymological dictionary of succulent plant names, Berlin: Springer, https://doi.org/ 10.1007/978-3-662-07125-0_1.

Epstein, M., 2017, 'Specimens and zoological nomenclature', Bionomina, vol. 12, no. 1, pp. 1-3, https://doi.org/ 10.11646/bionomina.12.1.1.

Ferreira, M.C., 1961, 'Catálogo dos Escarabídeos da Região Etiópica; Tribos Scarabaeini, Gymnopleurini e Oniticellini', Boletim da Sociedade Portuguesa de Ciências Naturais, vol. 7, pp. 225-236; vol. 8, pp. 17-157.

Forgie, S.A., Philips, T.K. \& Scholtz, C.H., 2005, 'Evolution of the Scarabaeini (Scarabaeidae: Scarabaeinae)', Systematic Entomology, vol. 30, pp. 60-96, https://doi.org/10.1111/ j.1365-3113.2004.00273.x.

Gillet, J.J.E., 1911, 'Coprophaga Africana; Descriptions d'espèces nouvelles et remarques diverses', Annales de la Societé Entomologique de Belgique, vol. 55, no. 11, pp. 308-312.

Harrison, J. du G. \& Philips, T.K., 2003, 'Phylogeny of Scarabaeus (Pachysoma MacLeay) stat. nov., and related flightless Scarabaeini (Scarabaeidae: Scarabaeinae)', Annals of the Transvaal Museum, vol. 40, pp. 47-71.

Harrison, J. du G., Scholtz, C.H. \& Chown, S.L., 2003, 'A revision of the endemic south-western African dung beetle subgenus Scarabaeus (Pachysoma), including notes on other flightless Scarabaeini', Journal of Natural History, vol. 37, pp. 305-355, https://doi.org/10.1080/713834683.

IUCN, 2012, IUCN Red List Categories and Criteria: Version 3.1, Second edition, Gland, Switzerland and Cambridge, UK: IUCN. iv + 32pp. Available at: https://www.iucnredlist.org/resources/categories-and-criteria [10 May 2021].

Janssens, A., 1938, 'Scarabaeini, Coleoptera Lamellicornia, Fam. Scarabaeidae', Exploration du Parc National Albert, Mission G.F. de Witte (1933-1935), vol. 21, pp. 68-72.

LaFleur, M. \& Gould, L., 2020, Lemur catta, The IUCN Red List of Threatened Species 2020: e.T11496A115565760. https://dx.doi.org/10.2305/IUCN.UK.2020-2.RLTS.T11496A 115565760.en [10 May 2021].

Lindenmayer, D. \& Scheele, B. (2017) 'Do not publish' Science vol. 356 no. 6340 , pp. 800-801. https://doi.org/10.1126/ science.aan1362.
Louis, E.E., Sefczek, T.M., Bailey, C.A., Raharivololona, B., Lewis, R. \& Rakotomalala, E.J., 2020, Propithecus verreauxi, The IUCN Red List of Threatened Species 2020: e.T18354A115572044. https://dx.doi.org/10.2305/IUCN. UK.2020-2.RLTS.T18354A115572044.en [10 May 2021].

Monaghan, M.T., Inward, D.J.G., Hunt, T. \& Vogler, A.P., 2007, 'A molecular phylogenetic analysis of the Scarabaeinae (dung beetles)', Molecular Phylogenetics and Evolution, vol. 45, pp. 674-692. https://doi.org/10.1016/j.ympev.2007.06.009.

Mostert, L.E. \& Holm, E., 1982, Notes on the flightless Scarabaeina (Coleoptera: Scarabaeidae) with a description of a new species', Cimbebasia A, vol. 5, no. 10, pp. 274-284.

Paulian, R. \& Lebis, E., 1960, 'Faune de Madagascar XI, Insectes, Coleopteres, Scarabaeidae', Publications de L'institut de Recherche Scientifique Tananarive Tsimbazaza, vol. 11, pp. 1-130.

Paulian, R., 1953, 'Recherches sur les insectes d'importance biologique à Madagascar. XX. Les Scarabaeini de Madagascar', Mémoires de I'Institut scientifique de Madagascar (E), vol. 3, pp. 24-27.

Philips, T.K., Pretorius, E. \& Scholtz, C.H., 2004, 'A phylogenetic analysis of dung beetles (Scarabaeinae: Scarabaeinae): unrolling an evolutionary history', Invertebrate Systematics, vol. 18, pp. 53-88. https://doi.org/10.1071/IS03030.

Rahagalala, P., Viljanen, H., Hottola, J. \& Hanski, I., 2009, 'Assemblages of dung beetles using cattle dung in Madagascar', African Entomology, vol. 17, pp. 71-89, https:// doi.org/10.4001/003.017.0109.

Scholtz, C.H., 1981, 'Aptery in Trox (Coleoptera: Trogidae): morphological changes and their relationship to habitat', Journal of the Entomological Society of Southern Africa, vol. 44, pp. 83-87.

Scholtz, C.H., 2000, 'Evolution of flightlessness in Scarabaeoidea', Mitteilungen aus dem Museum für Naturkunde in Berlin, Deutsch entomologische Zeitschrift, vol. 47, no. 1, pp. 5-28. https://doi.org/10.1002/mmnd.4800470102.

Sole, C.L., Wirta, H., Forgie, S.A. \& Scholtz, C.H., 2011, 'Origin of Madagascan Scarabaeini dung beetles (Coleoptera: Scarabaeidae): dispersal from Africa', Insect Systematics and Evolution, vol. 42, pp. 29-40. https://doi.org/ 10.1163/187631211X552800. 